\title{
Research Paper: The Moderating Role of Resilience in the Relationship Between Early Maladaptive Schemas and Anxiety and Depression Symptoms Among Firefighters
}

\author{
Hossein Khadem $^{1^{*}}$, Seyed Ali Motevalli Haghi ${ }^{2}$, Tohid Ranjbari' ${ }^{1}$ Abolfazl Mohammadi ${ }^{3}$ \\ 1. Department of Psychology, Faculty of Psychology and Education, University of Tehran, Tehran, Iran. \\ 2. Department of General Psychology, School of Psychology, University of Padova, Padova, Italy. \\ 3. Department of Psychiatry, School of Medicine, Tehran University of Medical Sciences, Tehran, Iran.
}

\begin{tabular}{|c|c|}
\hline $\begin{array}{l}\text { Use your device to scan } \\
\text { and read the article online }\end{array}$ & \\
\hline 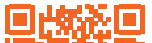 & the Relationship Between Early Maladaptive Schemas and Anxiety and Depression Symptoms Among Firefighters. Journal of \\
\hline ty & Practice in Clinical Psychology, 5(2), 133-140. https://doi.org/10.18869/acadpub.jpcp.5.2.133 \\
\hline retsin & dol ${ }^{\infty}$ : https://doi.org/10.18869/acadpub.jpcp.5.2.133 \\
\hline
\end{tabular}

Article info:

Received: 16 Dec. 2016

Accepted: 27 Feb. 2017
Keywords:

Early maladaptive schemas, Anxiety symptoms, Depressive symptoms, Resilience, Firefighter

\section{ABSTRACT}

Objective: This study aimed to examine the moderating role of resilience in the relationship between early maladaptive schemas and anxiety and depression symptoms among firefighters.

Methods: The study participants $(\mathrm{N}=225)$ were selected from the firefighters of Mashhad City through randomized sampling method. The data were collected by means of Young early maladaptive schemas questionnaire (long form), Conner-Davidson resilience scale, and anxiety and depression subscales of depression anxiety stress scale. A stepwise moderated regression was conducted in SPSS 23 to analyze the data.

Results: The regression analysis showed that resilience had a moderating role in the relationship between anxiety symptoms and impaired limits $(\mathrm{P}=0.009, \mathrm{t}=-2.70, \beta=-1.31)$, other- directedness $(\mathrm{P}=0.001, \mathrm{t}=-3.37, \beta=-1.65)$, and over vigilance and inhibition $(\mathrm{P}=0.002$, $\mathrm{t}=-3.18, \beta=-1.36)$. Resilience had also a moderating role in the relationship between depression symptoms and disconnection and rejection $(\mathrm{P}=0.002, \mathrm{t}=-3.14, \beta=-0.88)$, impaired limits $(\mathrm{P}=0.011, \mathrm{t}=-2.60, \beta=-1.24)$, other-directedness $(\mathrm{P}=0.000, \mathrm{t}=-4.12, \beta=-1.87)$ and over vigilance and inhibition $(\mathrm{P}=0.005, \mathrm{t}=-2.89, \beta=-1.25)$.

Conclusion: The results of the study revealed that resilience could decrease anxiety and depression symptoms by moderating the relationship between maladaptive schemas and anxiety and depression symptoms.

\section{Introduction}

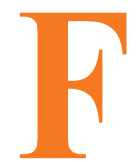

irefighting is one the most stressful careers around the world. Firefighters experience high pressure, high temperature, sleep deprivation, pain, and unstable job environ- ment. They also report many physical and mental stress symptoms (Throne, Bartholomew, Craig, \& Farrar, 2000). The continuity of stress in firefighting increases the possibility of developing post-traumatic stress disorder and other disorders caused by stressors such as anxiety and depression (Pelham, 2016). Generally, one of the

* Corresponding Author:

Hossein Khadem, MSc.

Address: Department of Psychology, Faculty of Psychology and Education, University of Tehran, Tehran, Iran.

Tel: +98 (939) 4149699

E-mail: hosseinekhadem@gmail.com 
predisposing factors in developing anxiety and depression disorders is the perception of events as stressful and harmful (Cohen, Janicki-Deverts, \& Miller, 2007). The early formed schemas in individuals determine the way they perceive events. Schemas are the cognitive shortcuts derived from past experiences, which interfere with daily routine experiences.

Early maladaptive schemas are formed in some people because of particular genetic features and also failure to satisfy emotional needs in their initial experience of childhood (Young, Klosko, \& Weishaar, 2003). These schemas are also activated in other similar situations and lead to anxiety and depression (Calvete, Orue, \& Hankin, 2014; Cámara \& Calvete, 2011; Lumley \& Harkness, 2007). However, it does not seem that the relationship between early maladaptive schemas and anxiety, depression symptoms is a simple linear relationship, because most people with different personality traits do not reveal any specific psychological signs on facing with stressful situations. In other words, they are resilient against the stress.

Resilience is a multidimensional and complex structure in response to stress, which researchers have not reached an agreement on its definition yet (Bonanno, Galea, Bucciarelli, \& Vlahov, 2007; Kent, Davis, \& Reich, 2013; Southwick, Litz, Charney, \& Friedman, 2011; Szanton \& Gill, 2010). American Psychiatric Association considers resilience as a process to adapt aptly to adversity, trauma, tragedy threats or other sources of stress (American Psychiatric Association, 2013). Accordingly, we could recognize two basic views about resilience; resilience as a consequence due to stress and resilience as a process meditating between trauma and stress (Southwick \& Charney, 2012). Therefore, the way anxiety is perceived by the firefighters who encounter traumatic events during their career, primarily depends on their personality structure, that is, their early maladaptive schemas. However, how firefighters react to this stress also depends on their resilience other than personality features as resilience is a component that demonstrates an individual's abilities and drives from his or her prior actions (Kent et al., 2013). Hence, the positive qualities of individuals and their active roles in fate affect how they face stress and traumatic events and whether or not they develop mental disorders such as anxiety or depression.

On the one hand, there is a negative relationship between disconnection and rejection, impaired autonomy and performance, other-directedness, impaired limits early maladaptive schemas, and resilience (Jazayeri, VatanKhah, \& Badiee, 2014). On the other hand, resilience is negatively correlated with anxiety and depres- sion symptoms (Beutel, Glaesmer, Wiltink, Marian, \& Brähler, 2009; Hjemdal, Vogel, Solem, Hagen, \& Stiles, 2010; Skrove, Romundstad, \& Indredavik, 2012). However, previous studies have mostly addressed the psychological components of firefighters at personality and symptom levels while in this study both levels were considered. Additionally, the investigation of both variables in different samples of Iranian firefighters was missing in the literature which was scrutinized in this study. Therefore, in this study, resilience was viewed in terms of a process and its moderating role was scrutinized in the relationship between early maladaptive schemas and anxiety and depression symptoms in an Iranian sample.

\section{Methods}

A cross-sectional design was used in this descriptive study. Using Krejcie and Morgan table (Krejcie \& Morgan, 1970), 225 firefighters were selected out of 543 firefighters in Mashhad City, Iran through randomized sampling method. The male participants with at least one year experience took part voluntarily in the study. However, firefighters who had a history of severe mental disorders or hospitalization in a mental hospital, or were taking psychiatric medicines at the time of conducting the study were excluded. The data were collected at the fire stations of Mashhad during day and night shifts in 24 days. To control the fatigue and order effect, the questionnaires were presented in two different forms with different subscale orders. The participants were presented with some information about the purpose of the study and confidentiality issues, then the instructions were given and it was made clear that there were no right or wrong answers. The participants were asked to fill out the questionnaires meticulously and provide true information about themselves. Each questionnaire needed around 20 minutes to fill out. While the subjects were answering the questions, the researcher was available to answer the probable questions. This study was conducted with the permission of the Fire Department of Mashhad City.

Connor-Davidson Resilience Scale: To measure resilience, the 25-item Conner-Davidson resilience scale was used. This scale measures individuals' ability to cope with threats and pressures and rated on a Likert-type scale from 0 (Never) to 4 (Always). It can distinguish individuals who are resilient against stress from those who are not. The Cronbach $\alpha$ coefficient was reported as 0.89 indicating an acceptable internal reliability. The reliability of this scale was confirmed by test-retest method and reported as 0.87 . Convergent and discriminant validity of this scale have been established by its concurrent administration with the Precept Stress Scale (PSS) and Ari- 
zona sex experience scale (Connor \& Davidson, 2003). The psychometric features of this scale in Chinese samples has also been confirmed (Yu \& Zhang, 2007). In an Iranian study, the validity coefficient of the test (correlation of each item with the total score) was obtained to be between 0.41 and 0.64 . Similarly, the reliability was calculated to be 0.89 by means of Cronbach $\alpha$ (Mohammadi, Jazayeri, Rafiei, Jokar, \& Pourshahnaz, 2005).

Young Schema Questionnaire: To assess the early maladaptive schemas, the long version of Young schema questionnaire with 205 predicative questions was utilized. The developers of the questionnaire have used the Cronbach $\alpha$ and test-retest method to calculate the reliability for each early maladaptive schema. The Cronbach $\alpha$ coefficient was reported to be in a range of 0.83 to 0.96 , and test-retest was calculated 0.50 to 0.82 for the non-clinical population (Schmidt, Joiner, Young, \& Telch, 1995). In Iran, the reliability of the long version of this questionnaire was estimated to be 0.86 and 0.91 by calculating the Cronbach $\alpha$ and split-half reliability (Yousefi \& Shirbagi, 2010).

Convergent and divergent validity of this questionnaire was calculated against questionnaires of psychological suffering questionnaire, positive and negative emotion, self-confidence, psychological vulnerability against depression and personal disorders. The correlation coefficients of $0.37,0.34,0.4,0.39,0.35$, and 0.36 were reported for each of the above questionnaires, respectively. Therefore, validity and reliability of this scale were also established in an Iranian sample (Yousefi \& Shirbagi, 2010).

Depression Anxiety Stress Scales (DASS): This test, designed by Lovibond and Lovibond in 1995, includes 21 items that measures 3 subscales of depression, anxiety and stress symptoms in 4-point Likert-type scale ranging from 0 to 3 . It is one of the most valid and reliable tests used to assess the negative affect symptoms (Daza, Novy, Stanley, \& Averill, 2002; Lovibond, 1998; Lovibond \& Lovibond, 1995; Norton, 2007).

For a sample of 278 non-clinical people, the reliability for the whole test and each of its subscales; depression, anxiety and stress, was reported to be $0.91,0.87,0.85$, and 0.89 , respectively. These coefficients were also estimated to be 0.93 for the whole test, 0.89 for depression, 0.91 for anxiety, 0.87 for stress in a clinical sample $(n=194)$. These reliability indices demonstrate a desirable internal consistency for the test and its subscales. Concurrent administration of subscales of depression, anxiety, and stress with Beck depression inventory, Beck anxiety scale, positive and negative affect schedule and mental health inventory on two groups of clinical and non-clinical participants established the concurrent, convergent, and divergent validity of DASS test. The results of Pearson correlation revealed a significantly positive correlation between depression, anxiety and stress subscales of DASS and Beck depression and anxiety, negative affects and psychological inability ( 0.44 to 0.61 ; $\mathrm{P}<0.001$ ). However, a significant negative correlation was found between subscales of DASS and positive affects and psychological welfare $(0.41$ to $0.58 ; \mathrm{P}<0.001)$ (Besharat, 2005). These results confirm the concurrent, convergent, and divergent validity of DASS scale.

\section{Results}

Before performing regression analysis and examining the moderating role of resiliency, it is necessary to examine the descriptive features of variables. In this regard, Table 1 presents some demographic features of age and educational level of firefighters. Table 2 shows the mean and standard deviation of the variables including schemas, resilience, anxiety and depression symptoms The results of Pearson correlation (Table 3 ) indicate a significant positive correlation $(\mathrm{P}<0.01)$ among all variables except resilience, which reveals a significant negative relationship. Nonetheless, a weak relationship exists between resilience and other-directedness variables $(0.14)$.

Stepwise hierarchical linear regression was utilized to investigate the relationship between early maladaptive schemas and anxiety, depression symptoms while moderated by resilience. The results (Table 4) indicate that resilience failed to moderate the relationship between anxiety symptoms and disconnection and rejection $(\mathrm{P}=0.271, \mathrm{t}=-1.10, \beta=-0.36)$ and impaired autonomy and performance $(\mathrm{P}=0.067, \mathrm{t}=-3.37, \beta=-0.19)$. However, resilience moderated the relationship between anxiety symptoms and schemas of impaired limits $(\mathrm{P}=0.009$, $\mathrm{t}=-2.70, \beta=-1.31)$, other-directedness $(\mathrm{P}=0.001, \mathrm{t}=-3.37$, $\beta=-1.65)$, and over vigilance and inhibition $(\mathrm{P}=0.002$, $\mathrm{t}=-3.18, \beta=-1.36)$. The moderating effect of resilience for each of impaired limits, other-directedness and over vigilance and inhibition were observed to be $5.7 \%$ $(\mathrm{P}=0.000, \Delta \mathrm{F}=2.08), 8.5 \%(\mathrm{P}=0.000, \Delta \mathrm{F}=0.78)$ and $7 \%$ $(\mathrm{P}=0.000, \Delta \mathrm{F}=2.66)$, respectively.

Furthermore, the results (Table 5) reveal that resilience failed to moderate the relationship between depression symptoms and impaired autonomy and performance $(\mathrm{P}=0.078, \mathrm{t}=-1.79, \beta=-0.40)$ while it moderated the relationship between depression symptoms and schema areas of disconnection and rejection $(\mathrm{P}=0.002, \mathrm{t}=-3.14$, $\beta=-0.88)$, impaired limits $(\mathrm{P}=0.011, \mathrm{t}=-2.60, \beta=-1.24)$, 
Table 1. Frequency distribution of age and educational level among study participants

\begin{tabular}{cccc}
\hline & & No. & \% \\
\hline Age, $y$ & $18-38$ & 128 & 56.8 \\
& $39-59$ & 82 & 36.4 \\
Educational level & $60-80$ & 15 & 6.6 \\
& Under diploma & 55 & 24.4 \\
& Diploma & 37.7 & 17.7 \\
& Bachelor & 85 & 12.8 \\
\hline
\end{tabular}

other-directedness $(\mathrm{P}=0.000, \mathrm{t}=-4.12, \beta=-1.87)$ and over vigilance and inhibition $(\mathrm{P}=0.005, \mathrm{t}=-2.89, \beta=-1.25)$. The moderating effect for each of the above schema areas (disconnection And rejection, impaired limits, other-directedness, over vigilance and inhibition) were estimated to be $4.9 \%(\mathrm{P}=0.000, \Delta \mathrm{F}=8.26), 5 \%(\mathrm{P}=0.000, \Delta \mathrm{F}=3.02), 11.3$ $\%(\mathrm{P}=-0.000, \Delta \mathrm{F}=-1.26)$ and $6 \%(\mathrm{P}=-0.000, \Delta \mathrm{F}=-3.59)$.

\section{Discussion}

The purpose of the study was to examine the moderating role of resilience in explaining the relationship between early maladaptive schemas and anxiety and depression symptoms in firefighters. The results revealed that resilience moderates the relationship between anxiety symptoms and schemas of impaired limits, other-directedness,and over vigilance and inhibition. Similarly, resilience demon- strated a moderating effect in explaining the relationship between depression symptoms and schemas of disconnection and rejection, impaired limits, other-directedness, and over vigilance and inhibition. Although previous studies have failed to explore the relationship between schemas and anxiety while moderated by resilience, they reported a significant negative correlation between resilience and early maladaptive schemas (Bamber \& McMahon, 2008; Eley et al., 2013; Keyfitz, Lumley, Hennig, \& Dozois, 2012), and a significant negative relationship between resilience and anxiety and depression symptoms (Degnan \& Fox, 2007; Hjemdal et al., 2010; Skrove et al., 2012) that are consistent with the findings of this study.

Two reasons can explain the results of this study. First, early maladaptive schemas through dysfunctional emotion regulation are mechanisms that produce stress, and are reasons

Table 2. Scores (mean and standard deviation) of schemas, resilience, anxiety and depression symptoms

\begin{tabular}{ccc}
\hline Variable & Mean & SD \\
\hline Resilience & 68.58 & 16.81 \\
\hline Disconnection and rejection & 55.45 & 17.32 \\
\hline Impaired autonomy and performance & 35.22 & 11.11 \\
Impaired limits & 27.60 & 7.02 \\
Other-directedness & 30.80 & 7.27 \\
Over vigilance and inhibition & 31.33 & 8.40 \\
Anxiety symptoms & 8.72 & 7.69 \\
Depression symptoms & 9.33 & 9.26 \\
\hline
\end{tabular}


Table 3. Correlation matrix between schemas, resilience, anxiety and depression symptoms

\begin{tabular}{|c|c|c|c|c|c|c|c|c|}
\hline Variable & $\begin{array}{l}\text { Resil- } \\
\text { ience }\end{array}$ & $\begin{array}{l}\text { Disconnec- } \\
\text { tion and } \\
\text { Rejection }\end{array}$ & $\begin{array}{l}\text { Impaired } \\
\text { Autonomy } \\
\text { and Per- } \\
\text { formance }\end{array}$ & $\begin{array}{l}\text { Im- } \\
\text { paired } \\
\text { Limits }\end{array}$ & $\begin{array}{l}\text { Other - Di- } \\
\text { rectedness }\end{array}$ & $\begin{array}{l}\text { Over Vigi- } \\
\text { lance and } \\
\text { Inhibition }\end{array}$ & $\begin{array}{c}\text { Anxiety } \\
\text { Symptoms }\end{array}$ & $\begin{array}{l}\text { Depression } \\
\text { Symptoms }\end{array}$ \\
\hline Resilience & 1 & & & & & & & \\
\hline $\begin{array}{l}\text { Disconnection and } \\
\text { rejection }\end{array}$ & $-0.47^{* *}$ & 1 & & & & & & \\
\hline $\begin{array}{l}\text { Impaired } \\
\text { autonomy and } \\
\text { performance }\end{array}$ & $-0.59^{* *}$ & $0.67^{* *}$ & 1 & & & & & \\
\hline Impaired limits & $-0.29^{* *}$ & $0.54^{* *}$ & $0.46^{* *}$ & 1 & & & & \\
\hline $\begin{array}{l}\text { Other-directed- } \\
\text { ness }\end{array}$ & -0.140 & $0.46^{* *}$ & $0.37^{* *}$ & $0.45^{* *}$ & 1 & & & \\
\hline $\begin{array}{l}\text { Over vigilance and } \\
\text { inhibition }\end{array}$ & $-0.33^{* *}$ & $0.52^{* *}$ & $0.47^{* *}$ & $0.58^{* *}$ & $0.63^{* *}$ & 1 & & \\
\hline Anxiety symptoms & $-0.50^{* *}$ & $0.640^{* *}$ & $0.70^{* *}$ & $0.37^{* *}$ & $0.37^{* *}$ & $0.52^{* *}$ & 1 & \\
\hline $\begin{array}{l}\text { Depression symp- } \\
\text { toms }\end{array}$ & $-0.55^{* *}$ & $0.71^{* *}$ & $0.70^{* *}$ & $0.35^{* *}$ & $0.38^{* *}$ & $0.47^{* *}$ & $0.72^{* *}$ & 1 \\
\hline
\end{tabular}

Table 4. Results of moderating regression analysis to evaluate the moderating role of resiliency in the relationship between early maladaptive schemas and anxiety symptoms

\begin{tabular}{|c|c|c|c|c|c|c|}
\hline & B & S.E & B & $\mathbf{t}$ & $\Delta \mathbf{R}^{2}$ & $\Delta \mathbf{F}$ \\
\hline Step 1 & & & & & 0.54 & $18.82^{* *}$ \\
\hline Disconnection and rejection & 0.28 & 0.04 & $0.64^{* *}$ & 7.15 & & \\
\hline Impaired autonomy and performance & 0.48 & 0.05 & $0.70^{* *}$ & 8.39 & & \\
\hline Impaired limits & 0.41 & 0.11 & $0.37^{* *}$ & 3.49 & & \\
\hline Other - directedness & 0.39 & 0.11 & $0.37^{* *}$ & 3.46 & & \\
\hline Over vigilance and inhibition & 0.48 & 0.09 & $0.52^{* *}$ & 5.30 & & \\
\hline Step 2 & & & & & 0.12 & $14.90^{* *}$ \\
\hline Resilience & -0.17 & 0.04 & $-0.37^{* *}$ & -3.86 & & \\
\hline Step 3 & & & & & 0.07 & $10.11^{* *}$ \\
\hline Disconnection and rejection $\times$ resilience & -0.16 & 0.04 & -0.36 & -1.10 & & \\
\hline Impaired autonomy and performance $\times$ resilience & -1.89 & 0.05 & -1.65 & -3.37 & & \\
\hline Impaired limits $\times$ resilience & -0.17 & 0.00 & $-1.31^{* *}$ & -2.70 & & \\
\hline Other-directedness $\times$ resilience & -0.01 & 0.00 & $-1.65^{* *}$ & -3.37 & & \\
\hline Over vigilance and inhibition $\times$ resilience & -0.01 & 0.00 & $-1.36^{* *}$ & -3.18 & & \\
\hline
\end{tabular}

${ }^{* *} \mathrm{P}<0.01,{ }^{*} \mathrm{P}<0.05$. 
Table 5. Results of moderating regression analysis to evaluate the moderating role of resiliency in the relationship between early maladaptive schemas and depression symptoms

\begin{tabular}{|c|c|c|c|c|c|c|}
\hline & B & S.E & B & $\mathbf{t}$ & $\Delta \mathbf{R}^{2}$ & $\Delta \mathrm{F}$ \\
\hline Step 1 & & & & & 0.61 & $22.25^{* *}$ \\
\hline Disconnection and rejection & 0.38 & 0.04 & $0.71^{* *}$ & 8.76 & & \\
\hline Impaired autonomy and performance & 0.58 & 0.07 & $0.70^{* *}$ & 8.39 & & \\
\hline Impaired limits & 0.49 & 0.14 & $0.35^{* *}$ & 3.25 & & \\
\hline Other-directedness & 0.39 & 0.11 & $0.31^{* *}$ & 3.39 & & \\
\hline Over vigilance and inhibition & 0.52 & 0.11 & $0.47^{* *}$ & 4.64 & & \\
\hline Step 2 & & & & & 0.07 & $2.90^{* *}$ \\
\hline Resilience & -0.24 & 0.05 & $-0.44^{* *}$ & -4.56 & & \\
\hline Step 3 & & & & & 0.06 & $2.79^{* *}$ \\
\hline Disconnection and rejection $\times$ resilience & -0.00 & 0.00 & $-0.88^{* *}$ & -3.14 & & \\
\hline Impaired autonomy and performance $\times$ resilience & 0.89 & 0.06 & -0.40 & -1.79 & & \\
\hline Impaired limits $\times$ resilience & -0.02 & 0.00 & $-1.24^{* *}$ & -2.60 & & \\
\hline Other-directedness $\times$ resilience & -0.02 & 0.00 & $-1.87^{* *}$ & -4.12 & & \\
\hline Over vigilance and inhibition $\times$ resilience & -0.01 & 0.00 & $-1.25^{* *}$ & -2.89 & & \\
\hline
\end{tabular}

${ }^{* *} \mathrm{P}<0.01,{ }^{*} \mathrm{P}<0.05$.

behind inappropriate use of strategies against stress. Therefore, failure to satisfy the emotional needs in childhood experience contributes to the formation of low resilience as a personality trait following dysfunctional emotion regulation (Eberhart, Auerbach, Bigda-Peyton, \& Abela, 2011). As the resilience of an individual against stressful and harmful events reduces, the vulnerability increases, which raises the possibility of anxiety and depression symptoms (Connor \& Davidson, 2003; Hjemdal et al., 2010).

The second reason can be traced back to the neurological features of this relationship. On the one hand, 11 neurological mediators have been recognized as biopsycho responses to high stress that relate to vulnerability and resilience. These neurological processes are similar to personality traits related to resilience among which the early maladaptive schemas can be identified (Charney, DeJesus, \& Manji, 2004).

On the other hand, research has revealed that the neurons, which act as mediators in the formation of resilience, are causes for the existence of another neurological cycle that mediates formation of strategies to cope with problem-focused stress that finally leads to an individual's mental health (Feder, Nestler, \& Charney, 2009).
The results of this study also indicated that resilience fails to moderate the correlation between impaired autonomy and performance and anxiety and depression symptoms. It appears that as the mentioned schema reduces an individual's self-confidence, it can directly lead to excitement disorders, without mediation of any other variables (Mann, Hosman, Schaalma, \& De Vries, 2004).

This study had several practical implications. First, firefighters' selection can be conducted by administering a psychological assessment that measures their personal traits and level of resilience against stress to prevent psychological and physical damage to them and enhance their efficacy. Firefighters who have early maladaptive schema of impaired autonomy and performance, as well as low resilience against stress are unsuitable for firefighting candidacy because they are more prone to stress and anxiety.

Second, psychological interventions based on recognition and improvement of maladaptive schema seems necessary for in-service firefighters who have early maladaptive schema. If this is impossible, it is imperative to educate strategies to deal with problem-focused stress to enhance the resilience. 
This study has several limitations out of which the following ones are worth mentioning. First, as the results are limited to a sample of firefighters in Mashhad, the findings should be generalized with caution. Second, this study failed to include all contributing factors while resilience is a multidimensional construct, involving several variables. Third, as the responses to questionnaires could be affected by the mood and relations of individuals, they might fail to represent individuals' general state. Furthermore, negative mood can lead to the recollection of negative points and weaknesses. Fourth, this study utilized correlation-based design to examine the moderating effect, which prevents causal inferences. Future research can investigate the psychological (personal, emotional, cognitive, and behavioral), cultural-social, and physical dimensions of resilience in firefighting and other stressful jobs to establish more fine-tuned criteria to predict better resilience in stressful jobs.

\section{Acknowledgements}

This research did not receive any specific grant from funding agencies in the public, commercial, or not-forprofit sectors.

\section{Conflict of Interest}

The authors declared no conflicts of interest.

\section{References}

American Psychiatric Association. (2013). Diagnostic and statistical manual of mental disorders (DSM-5®). New York: American Psychiatric Pub.

Bamber, M., \& McMahon, R. (2008). Danger-early maladaptive schemas at work: The role of early maladaptive schemas in career choice and the development of occupational stress in health workers. Clinical Psychology \& Psychotherapy, 15(2), 96-112. doi: 10.1002/cpp.564

Besharat, M. (2005). [Evaluating the psychometric properties of depression anxiety stress scale-21 in clinical and normal samples (Persian)]. Tehran: University of Tehran.

Beutel, M. E., Glaesmer, H., Wiltink, J., Marian, H., \& Brähler, E. (2009). Life satisfaction, anxiety, depression and resilience across the life span of men. The Aging Male, 13(1), 32-9. doi: $10.3109 / 13685530903296698$

Bonanno, G. A., Galea, S., Bucciarelli, A., \& Vlahov, D. (2007) What predicts psychological resilience after disaster? The role of demographics, resources, and life stress. Journal of Consulting and Clinical Psychology, 75(5), 671-82. doi: 10.1037/0022006x.75.5.671
Calvete, E., Orue, I., \& Hankin, B. L. (2014). A longitudinal test of the vulnerability-stress model with early maladaptive schemas for depressive and social anxiety symptoms in adolescents. Journal of Psychopathology and Behavioral Assessment, 37(1), 85-99. doi: 10.1007/s10862-014-9438-x

Cámara, M., \& Calvete, E. (2011). Early maladaptive schemas as moderators of the impact of stressful events on anxiety and depression in university students. Journal of Psychopathology and Behavioral Assessment, 34(1), 58-68. doi: 10.1007/s10862011-9261-6

Charney, D. S., DeJesus, G., \& Manji, H. K. (2004). Cellular plasticity and resilience and the pathophysiology of severe mood disorders. Dialogues in Clinical Neuroscience, 6(2), 217. PMID: 22033657

Cohen, S., Janicki-Deverts, D., \& Miller, G. E. (2007). Psychological stress and disease. JAMA, 298(14), 1685. doi: 10.1001/ jama.298.14.1685

Connor, K. M., \& Davidson, J. R. T. (2003). Development of a new resilience scale: The Connor-Davidson resilience scale (CD-RISC). Depression and Anxiety, 18(2), 76-82. doi: 10.1002/ da.10113

Daza, P., Novy, D. M., Stanley, M. A., \& Averill, P. (2002). Journal of Psychopathology and Behavioral Assessment, 24(3), 195-205. doi: 10.1023/a:1016014818163

Degnan, K. A., \& Fox, N. A. (2007). Behavioral inhibition and anxiety disorders: Multiple levels of a resilience process. Development and Psychopathology, 19(03), 729. doi: 10.1017/ s0954579407000363

Eberhart, N. K., Auerbach, R. P., Bigda-Peyton, J., \& Abela, J. R. Z. (2011). Maladaptive Schemas and Depression: Tests of Stress Generation and Diathesis-Stress Models. Journal of Social and Clinical Psychology, 30(1), 75-104. doi: 10.1521/ jscp.2011.30.1.75

Eley, D. S., Cloninger, C. R., Walters, L., Laurence, C., Synnott, R., \& Wilkinson, D. (2013). The relationship between resilience and personality traits in doctors: Implications for enhancing well being. PeerJ, 1(216). doi: 10.7717/ peerj.216

Feder, A., Nestler, E. J., \& Charney, D. S. (2009). Psychobiology and molecular genetics of resilience. Nature Reviews Neuroscience, 10(6), 446-57. doi: 10.1038/nrn2649

Hjemdal, O., Vogel, P. A., Solem, S., Hagen, K., \& Stiles, T. C. $(2010)$. The relationship between resilience and levels of anxiety, depression, and obsessive-compulsive symptoms in adolescents. Clinical Psychology \& Psychotherapy, 18(4), 314-321. doi: $10.1002 /$ cpp.719

Jazayeri, S., Vatankhah, H., \& Badiee, M. (2014). [The relationship between defense styles and early maladaptive schemas with resilience in boy students of high school in Tehran City (Persian)]. Journal of Thought \& Behavior in Clinical Psychology, $8(30), 7-16$

Kent, M., Davis, M. C., \& Reich, J. W. (2013). The resilience handbook: Approaches to stress and trauma. Abingdon: Routledge.

Keyfitz, L., Lumley, M. N., Hennig, K. H., \& Dozois, D. J. A. (2012). The role of positive schemas in child psychopathology and resilience. Cognitive Therapy and Research, 37(1), 97-108. doi: $10.1007 /$ s10608-012-9455-6 
Krejcie, R. V., \& Morgan, D. W. (1970). Determining sample size for research activities. Educational and Psychological Measurement, 30(3), 607-10. doi: 10.1177/001316447003000308

Lovibond, P. F. (1998). Long-term stability of depression, anxiety, and stress syndromes. Journal of Abnormal Psychology, 107(3), 520-6. doi: 10.1037/0021-843x.107.3.520

Lovibond, P. F., \& Lovibond, S. H. (1995). The structure of negative emotional states: Comparison of the Depression Anxiety Stress Scales (DASS) with the Beck depression and anxiety inventories. Behaviour Research and Therapy, 33(3), 335-43. doi: 10.1016/0005-7967(94)00075-u

Lumley, M. N., \& Harkness, K. L. (2007). Specificity in the relations among childhood adversity, early maladaptive schemas, and symptom profiles in adolescent depression. Cognitive Therapy and Research, 31(5), 639-57. doi: 10.1007/ s10608-006-9100-3

Mann, M., Hosman, C. M. H., Schaalma H. P., de Vries, N. K. (2004). Self-esteem in a broad-spectrum approach for mental health promotion. Health Education Research, 19(4), 357-372. doi: $10.1093 /$ her/cyg041

Mohammadi, M., Jazayeri, A. R., Rafiei, A. H., Jokar, B., \& Pourshahnaz, A. (2005). [A study on the factors affecting resilience in people at risk of substance abuse (Persian)]. Modern Psychological Research, 1(2-3), 203-24.

Norton, P. J. (2007). Depression Anxiety and Stress Scales (DASS-21): Psychometric analysis across four racial groups. Anxiety, Stress \& Coping, 20(3), 253-65. doi: 10.1080/10615800701309279.

Pelham, B. (2016). Saving our heroes: A longitudinal study of mental disorders within the fire service (BA thesis). Claremont: Claremont Graduate University.

Schmidt, N. B., Joiner, T. E., Young, J. E., \& Telch, M. J. (1995) The schema questionnaire: Investigation of psychometric properties and the hierarchical structure of a measure of maladaptive schemas. Cognitive Therapy and Research, 19(3), 295-321. doi: 10.1007/bf02230402

Skrove, M., Romundstad, P., \& Indredavik, M. S. (2012). Resilience, lifestyle and symptoms of anxiety and depression in adolescence: The Young-HUNT study. Social Psychiatry and Psychiatric Epidemiology, 48(3), 407-16. doi: 10.1007/s00127012-0561-2

Southwick, S. M., \& Charney, D. S. (2012). The science of resilience: Implications for the prevention and treatment of depression. Science, 338(6103), 79-82. doi: 10.1126/science.1222942

Southwick, S. M., Litz, B. T., Charney, D., \& Friedman, M. J. (2011). Resilience and mental health: Challenges across the lifespan. Cambridge: Cambridge University Press. doi: 10.1017/ cbo9780511994791

Szanton, S. L., \& Gill, J. M. (2010). Facilitating resilience using a society-to-cells framework. Advances in Nursing Science, 33(4), 329-43. doi: 10.1097/ans.0b013e3181fb2ea2

Throne, L. C., Bartholomew, J. B., Craig, J., \& Farrar, R. P. (2000). Stress reactivity in fire fighters: An exercise intervention. International Journal of Stress Management, 7(4), 235-46. doi 10.1023/a:1009574428627

Young, J. E., Klosko, J. S., \& Weishaar, M. E. (2003). Schema therapy: A practitioner's guide. New York: Guilford Press.
Yousefi, N., \& Shirbagi, N. (2010). [Validating the Young Early Maladaptive Schema Questionnaire (YEMSQ) among students (Persian)]. Iranian Journal of Psychiatry and Behavioral Sciences, $4(1), 38-46$

Yu, X., \& Zhang, J. (2007). Factor analysis and psychometric evaluation of the connor-davidson resilience scale (CD-RISC) with Chinese people. Social Behavior and Personality: An International Journal, 35(1), 19-30. doi: 10.2224/sbp.2007.35.1.19 